\title{
DESAGREGANDO A MEDIAÇÃO: TECNOLOGIAS E ATMOSFERAS RELIGIOSAS
}

Bruno Reinhardt ${ }^{1}$

${ }^{1}$ Universidade Federal de Santa Catarina, Florianópolis/SC, Brasil

Máquina de oração: religião entre organismo e mecanismo

A primeira vez que encontrei esta inusitada expressão - máquina de oração - foi durante minha pesquisa de campo em Gana, centrada na pedagogia religiosa de ministros pentecostais. Seu referente, no entanto, não era nenhuma máquina propriamente dita (Blanton 2016), mas um homem, um profeta popular, que eu chamarei aqui de Ato, e cujas técnicas e tecnologias de oração me ajudarão a refletir sobre a relação entre o orgânico e o mecânico nesta espiritualidade. Conheci Ato quando visitava a Escola de Excelência Profética, uma escola para pastores localizada na vizinhança de Lapaz, Acra. Ela atendia a um pequeno grupo de dez alunos, em sua maioria ministros aprendizes interessados em "afinar" suas dádivas proféticas ao "sentar-se sob os pés" de ministros mais experientes. As atividades incluíam aulas sobre o chamado e a missão dos profetas, um constante compartilhamento de testemunhos sobre modos próprios e impróprios de se profetizar e um grande número de sessões de oração, tanto dentro da igreja onde nos encontrávamos quanto em retiros localizados na região metropolitana de Acra, como a floresta Achimota e a montanha Akoko. A escola organizava encontros diários por três meses, um período em que estudantes, instrutores e antropólogo deveriam jejuar entre o amanhecer e as 6 da tarde e manter-se sexualmente abstinentes. 
As escolas bíblicas de Acra são lugares para se cultivar a devoção pessoal, adquirir habilidades religiosas e receber dádivas espirituais, assim como nódulos de redes religiosas. O Profeta Patrick e o apóstolo Atiemo, as lideranças desta associação, frequentemente convidavam outros ministros para falar sobre suas experiências, transferir conhecimentos e impor suas mãos sobre seus pupilos, desejosos por uma impartição da unção profética. ${ }^{1}$ O Profeta Ato foi um desses convidados, tendo sido introduzido como um "grande homem de Deus", que levava uma "vida de oração", a ponto de tornar-se conhecido na comunidade pentecostal local (sempre bemhumorada) como "Máquina de Oração" (Prayer Machine). Seu apelido era um reconhecimento público da capacidade deste profeta de "trabalhar na oração", dedicar-se a longas e dispendiosas horas de orações em línguas e assim catalisar experiências carismáticas profundas. O Profeta Boateng adicionou às credenciais de "Máquina de Oração" jejuns integrais que poderiam durar até quarenta dias, "como Jesus no deserto".

O apelido de profeta Ato é apenas um exemplo de como pentecostais em Gana pensam o mundo e a si mesmos através de figuras tecnológicas (Henare et al. 2007). Esse fenômeno vai além da automaticidade que equipara máquinas a corpos em intensa devoção, como exemplificado pelo hábito generalizado de se falar sobre o poder do Espírito Santo através de fenômenos elétricos, como "fluxo", "choque" e "recarga", ou sobre sonhos de origem carismática como "fotografias" e "telas de vídeo" utilizadas por Deus para se comunicar com os homens. Essas figuras retóricas frequentemente mobilizam propriedades orgânicas e mecânicas de forma intercambiável enquanto qualisignos (Peirce 1955; Munn 1992: 74-104) que permitem aos fiéis refletirem e persuadirem outros sobre componentes ontológicos de seu mundo religioso. ${ }^{2}$ Se, de acordo com o apóstolo Paulo, "desde a criação do mundo os atributos invisíveis de Deus, seu eterno poder e sua natureza divina têm sido vistos claramente, sendo compreendidos por meio das coisas criadas" (Romanos 20:21, NVI), pentecostais em Gana fazem uso dessa dádiva cognitiva através das criações naturais de Deus e dos artifícios criados pelos humanos. O mesmo se observa no caso das obras do demônio, como a bruxaria, cuja capacidade de ação a distância é frequentemente referida como "controle remoto africano".

A aula do profeta Ato naquele mesmo dia exemplificou o hibridismo discursivo a que me refiro. Ele começou em um registro orgânico e definiu a oração como "comida espiritual", dando a esta expressão uma dimensão menos metafórica quando testemunhou empolgado sobre seu alto nível de energia corporal após longos períodos de jejum, fenômeno que só poderia ter "uma causa espiritual". O profeta expandiu esse léxico ao transitar 
do nutricional para o atlético. Após citar a prescrição de Paulo para "orar constantemente", ele nos alertou que "a oração não é uma pílula que você toma quando está passando por dificuldades. A oração é um músculo que os cristãos devem exercitar todo dia". Ele proveu os estudantes de algumas técnicas que costuma administrar à sua congregação, como a "maratona de oração" que organiza mensalmente, que os tem ajudado a desenvolver seus "músculos espirituais" e a aumentar a sua "estamina espiritual".

Demonstrando seu raciocínio ciborgue, o Profeta Ato mudou então para um registro mecânico. Ele desenhou um rádio no desgastado quadro negro portátil da escola e começou a explorar, através do estilo dialógico que caracteriza a pregação pentecostal, algumas similitudes entre este aparelho e a dádiva profética. Disse ele, em uma mistura de akan twi ${ }^{3}$ e inglês:

Profetas são como rádios, amém? As ondas do ar estão cheias de informação, mas, para capturá-las, vocês têm que esticar as suas antenas e sintonizar seus aparelhos. Amén? Estudantes: Amén. P: Então, o que acontece se vocês não sintonizarem seus rádios? Vocês escutam alguma coisa? E: Não... P: Não, apenas barulho. E vocês sabem como sintonizar os seus rádios para receber do Senhor? Amados, não há outra forma: santificação, jejum e oração. Vocês querem ser bons rádios para o Senhor? E: Sim, amém, aleluias. P: O Senhor quer falar com vocês. Na verdade, ele já está falando. Neste exato momento. Eu vejo a mão do Senhor em seu ministério! E: Eu recebo! P: [Após rapidamente falar em línguas] O problema é que nossos rádios não estão sintonizados na estação do Senhor como eles deveriam estar. Alguns estão escutando apenas o barulho dos falsos profetas. E: Sim. P: Outros estão escutando Deus aqui e ali. Precisamos melhorar essa relação, sintonizar nossos rádios pra escutá-lo a todo tempo. Amém? Vocês têm que se tornar cristãos "orantes" [prayerful].

Antes de abordar algumas das inclinações da espiritualidade e do corpo Pentecostal que permitem esse tipo de hibridismo discursivo, é importante destacar que as tecnologias têm sido incorporadas pela retórica deste grupo religioso porque se estabeleceram em Gana como o que o ecólogo das mídia Mark Hansen chama de um "ambiente para a vida" (Hansen 2006:199). Nesse sentido, especulações sobre religião e tecnologia em termos de analogias, tipologias, metáforas e isomorfismos se desenrolam em um contexto em que esses domínios, aparentemente distintos, tornaram-se profundamente entrelaçados na prática. Birgit Meyer (2015a) ilustra essa dependência ecológica através de um caso ilustrativo, que aconteceu durante um de seus trabalhos de campo em Acra. Ela narra como um apagão interrompeu um até então visceral culto de oração em línguas, expondo para todos como a infraestrutura de fios, microfones, sistemas de som e luz 
teria se tornado um componente intrínseco do que ela chama de "formas sensacionais" (sensational forms) pentecostais, ou "modos relativamente fixos para invocar e organizar o acesso ao transcendental" (Meyer 2015a: 151). Se anteriormente destaquei que, para os pentecostais de Gana, o Espírito Santo opera como a eletricidade, aqui aprendemos que ele também opera crescentemente através dela.

Estendendo o argumento de Meyer, poderíamos dizer que, sem extensões (McLuhan 1967) tecnológicas de toda ordem, o próprio reavivamento pentecostal em Gana teria sido bem mais reduzido (Gifford 2004). A última e mais potente onda reavivalista, associada aos chamados ministérios carismáticos, seguiu de perto a redemocratização do país no início dos anos 1990. Essa mudança estrutural permitiu aos ganenses maior exercício de liberdade de associação e liberalizou uma esfera pública antes controlada estritamente pelo Estado, abrindo-a para investimentos privados e novas vozes. Os pentecostais encontraram nessas mudanças uma oportunidade para acessar novas doutrinas circuladas por ministros internacionais, como as teologias da prosperidade, e expandir estrategicamente o alcance de seu proselitismo através de "ministérios de mídia", baseados na imprensa, no rádio e na TV. Eles reanimaram e literalmente converteram para Cristo a indústria cultural local, antes dilapidada pelas crises econômicas da década de 1980.

O Profeta Ato é um dos muitos frutos deste reavivamento. Ele pensa a sua fé através das tecnologias, em grande parte porque ele as incorporou ao seu ministério. Ato é frequentemente convidado a pregar, profetizar ou orar em programas populares de rádio em Acra e domina a retórica radiofônica. Ele está constantemente ocupado com seu celular, trabalhando no que ele chama, em tom jocoso, de sua "linha telefônica dos viciados em oração". Através deste aparelho, o profeta presta aconselhamento, ora a distância, interpreta sonhos e "cancela" problemas pessoais "em nome de Jesus". Ele também é ativo no Facebook, tendo cerca de 4 mil seguidores, que respondem empolgados, com améns e aleluias, às suas postagens contendo citações bíblicas, palavras de encorajamento, profecias, testemunhos e registros fotográficos de experiências miraculosas, orações com vários propósitos e pôsteres digitais divulgando seus cultos, convenções, reavivamentos e linha telefônica. Apesar de seu ministério não ser grande o suficiente para financiar DVDs ou programas de televisão, o profeta sempre aponta um pastor assistente para gravar em vídeo suas performances, encontrando em sites com Youtube uma plataforma para avançar seu humilde, porém efetivo, "ministério de mídia". 
O Profeta Ato me convidou para conhecer a sua casa, localizada na vizinhança de Mallam Junction. Lá, ele me apresentou orgulhoso a sua enorme coleção de livros devocionais, escritos por ministros locais e internacionais, geralmente vendidos a preços módicos em versões piratas. Conversamos também sobre a sua ampla coleção de CDs e DVDs com música gospel, sermões e filmes cristãos. Esse arquivo transnacional de textos, imagens e vídeos é parte central de seu métier, já que dele o profeta pode retirar temas e mesmo estilos oratórios e estéticas para replicar em suas performances no púlpito. Ele também me mostrou seu "quarto de oração", onde se isola periodicamente de modo a escapar das distrações da vida doméstica. Seus componentes representavam bem a cultura material de um profeta pentecostal contemporâneo: um grande pôster de Jesus na parede, uma TV com DVD, manuais de oração espalhados pelo chão, uma "cadeira de oração" dobrável, que ele levava para retiros espirituais, além de garrafas de óleo ungido, potes de mel e uma coleção de shofars, ${ }^{4}$ substâncias e objetos que fazem parte de seu repertório litúrgico.

Para minha surpresa, descobri que Máquina de Oração também tinha suas próprias máquinas de oração: um tapete de oração eletrônico (provavelmente concebido para o mercado islâmico), com caixas de som embutidas, e um massageador de costas elétrico, ambos feitos na China. De acordo com ele, o massageador tinha a finalidade de "estimular a circulação" e promover relaxamento enquanto meditava "no Espírito", e que seu "tapete sagrado com um som bombástico de gueto" tinha a finalidade de "acendê-lo" com sermões e louvações enquanto ele orava. Todos esses artefatos e aparelhos e o quarto de oração em sua totalidade foram definidos pelo profeta de terem a finalidade de ajudá-lo a "submeter-se" a Deus, a "buscar a sua face", a "saturar-se" em ou a "canalizar" seu poder espiritual.

Com as diversas cenas acima, minha intenção foi simplesmente evocar o paralelismo entre discursos sobre a oração em termos de organismo e mecanismo e o entrelaçamento concreto entre esses domínios em Gana. O problema de como religião e tecnologia se relacionam foi deixado propositalmente em aberto, e eu elaboro sobre ele adiante. Seguindo Hirschkind (2011) e Beliso-de Jésus (2015), eu evitarei chamar essa relação de "mediação" (Engelke 2010) por diversos motivos, o mais importante deles sendo a qualidade atmosférica da fé e da concepção pentecostal de presença (Engelke 2007) ou agência divina. Destaco que as atmosferas pentecostais dissolvem de maneira persistente as fronteiras entre mediadores discerníveis - orgânicos e mecânicos - na fluidez do medium ecológico (Gibson 1979; Ingold 2011). Isto me levará a argumentar que o foco ecológico dos pentecostais em arranjos atmosféricos demanda um conjunto 
alternativo de conceitos - como os de virtualidade e possibilidades de ação [affordances] - capaz de desagregar os usos heterógenos condensados e homogeneizados pela noção de mediação. Eu apresento estes conceitos ao examinar etnograficamente o lugar da tecnologia em dois tipos de atmosferas reavivalistas pentecostais, e concluo explorando como as atmosferas religiosas provêm uma solução específica para a questão da imediação (Eisenlohr 2009; Meyer 2015a) ou, como prefiro chamar, transcendência (Reinhardt 2015; 2016b), no pentecostalismo enquanto religião material.

\section{Mediação: a religião-enquanto-mídia}

O conjunto de trabalhos que se dedicou de forma mais sistemática ao estudo da relação entre religião e tecnologia nas últimas décadas é aquele apelidado por Engelke (2010) de "virada midiática" nos estudos da religião (veja-se também Machado 2015). A preocupação básica deste vasto conjunto de trabalhos tem sido articular uma terceira via para além de posturas opositivas ou instrumentalistas acerca desses domínios, o que Stolow (2013) resume como "ator religioso - tecnologia = resultado religioso" e "ator religioso + tecnologia = resultado religioso". Enquanto a primeira equação define a religião como algo incomensurável com a tecnologia, já que fundamentada em significados últimos e valores imateriais, a segunda destaca como a religião utilizaria a tecnologia apenas como um meio instrumental passivo para fins distintamente religiosos. Essa terceira via é encontrada em uma identificação ontológica entre a religião e as tecnologias da comunicação como igualmente assentadas em processos de mediação. Em um artigo fundacional para esta escola, Stolow (2005) resume tal argumento afirmando que

O problema com a frase "religião e mídia" é que se trata de um pleonasmo. Seja enquanto transmissão de uma essência numinosa para uma comunidade de fiéis, a presentificação do divino em experiências pessoais, ou o desenrolar de circuitos miméticos de trocas entre poderes transcendentais e praticantes terrenos, a "religião" apenas se manifesta através de processos de mediação. Através da sua história, em miríades de formas, a comunicação com e sobre "o sagrado" sempre foi posta em prática através de textos, gestos rituais, imagens e ícones, arquitetura, música, incenso, vestimentas especiais e outros objetos de veneração, marcas corporais, línguas vibrantes e outras parte do corpo (:125). 
Segundo esta ótica, a religião sempre foi composta por técnicas e tecnologias cujo fim último seria mediar forças transcendentais, logo o sentimento de novidade acerca da religião tecnologicamente mediada deveria ser diluído por uma consciência mais aguçada acerca do vínculo genético articulando esses domínios aparentemente distintos ou, de acordo com o resumo de Stolow, mudando o registo deste debate de "religião e mídia" para "religião-enquanto-mídia". Essa guinada analítica é embasada em uma definição extensa do medium, que inclui elementos mais convencionais da materialidade religiosa - como corpos, ícones, substâncias, estátuas e textos sagrados - lado a lado com novas tecnologias de comunicação, o último representando apenas uma subcategoria do primeiro (Meyer 2011).

Essa posição, baseada em argumentos anteriores de Jacques Derrida (2000) e Hent De Vries (2001), tem diversas virtudes. Primeiro, ela pluraliza narrativas dominantes sobre o chamado "desencantamento" tecnológico da modernidade. $\mathrm{O}$ fato é que a tecnologia moderna não apenas desvelou a mecânica fria da matéria extensa através de processos ocularcêntricos de objetificação, mensuração e reprodução técnica, mas também reanimou e mesmo amplificou sentimentos de reverência e fascínio através de automatismos milagrosos, vozes desincorporadas, imagens fantasmagóricas e afetos desterritorializados (Taussig 1992; Meyer \& Pels 2003; Delbourgo 2006; Bensaude-Vincent \& Blondel 2008). Nessa ótica, o paradigma da religião-enquanto-mídia é especialmente adequado para uma reflexão acerca de eventos interseccionais, religiosos-seculares, como "a verdade profunda que subjaz à definição de celebridades produzidas e mediadas pela mídia de massa como 'ícones' e 'ídolos'" (De Vries 2001:22), ou as semelhanças estruturais entre milagres e efeitos especiais (De Vries 2001:28; veja-se também Meyer 2015b).

Segundo, o paradigma da religião-enquanto-mídia provê recursos para se explorarem em uma escala ampla as várias formas através das quais as tecnologias se tornaram intrínsecas a determinadas tradições religiosas na modernidade, seja como meios para se perceberem e se sentirem agências espirituais (Schmidt 2000), seja como instrumentos para se cultivarem sensibilidades devotas (Hirschkind 2006) e agregadores materiais de públicos religiosos (Meyer \& Moors 2006; Cunha 2007). Inovações como o "telégrafo espiritual" dos espíritas europeus (Stolow 2008), o "radio spiritual" dos protestantes liberais norte-americanos (Klassen 2011), e o uso de fotografias em práticas de cura no leste africano (Behrend 2003) corroboram a tese de que a tecnologia não é apenas usada pela religião de forma instrumental, mas também englobada por sua medialidade própria. Mas o que exatamente se quer dizer com "mediação", este termo em que comungam tecnologia e religião no paradigma da religião-enquanto-mídia? 


\section{Virtualidades, atmosferas e affordances}

A virada midiática nos estudos da religião reanimou a sua relevância social e política, além de ter promovido um amplo campo de estudos comparativos sobre o tema. Mas ela não escapou de visadas mais críticas. De acordo com Horsfield, por exemplo, "com tal visão ampla da mediação social e religiosa, suas ricas descrições podem se tornar tão difusas a ponto de perder qualquer valor estratégico" (2008:114). Engelke reconhece que a tese da religião-enquanto-mídia "não avança muito a discussão sobre poder institucional" (2010:375). Charles Hirschkind (2011) vai além e argumenta que uma abordagem mais pragmática para a religião poderia até dispensar a noção de mediação: "Poderíamos dizer, por exemplo, que o Corão impresso não medeia a tradição islâmica; a variedade de modos com que o Corão é tocado, segurado, cuidado, lido, recitado, apreciado, assim como impresso e circulado são simplesmente parte intrínseca do modo de vida islâmico (a bola de futebol não medeia esse jogo; ela é um elemento constitutivo e necessário dentro dele)" (Hirschkind 2011:93). Beliso-de-Jésus (2015) caminha em direção similar quando provincializa o conceito de mediação ao destacar suas inclinações judaico-cristãs. Referindo-se à sensibilidade espiritualizada dos praticantes da Santeria cubana às emissões de vídeo, ela argumenta que, "diferente da 'mediação' entre o aqui e o além [...], as relações com o vídeo na Santeria expandem a copresença eletrificante de espíritos e praticantes" (:43). A dinâmica da Santeria de "andar com" (:75) divindades seria irredutível ao modelo de sujeito religioso generalizado pelo paradigma da religião-enquanto-mídia: alguém que se projeta para ou que é interpelado por um Outro transcendente através de um mediador orgânico ou mecânico.

Enquanto todos esses críticos corroboram a rejeição de teorias meramente instrumentalistas sobre a relação entre religião e tecnologia, baseadas em noções imaterialistas de religião e simplistas de causalidade, eles também se sentem incomodados com aquilo que se perde com a guinada repentina proposta pelo paradigma da religião-enquanto-mídia, da incomensurabilidade para uma total identificação ontológica entre esses fenômenos. Pode-se dizer que a mediação de fato perpassa todos os fenômenos humanos, mas isso dependente, claro, de como definimos o medium. Afinal de contas, sem, por exemplo, a mediação do meio aéreo, não poderíamos ver, ouvir ou falar. Essa qualidade ubíqua torna a noção de mediação estratégica quando se trata de problematizar fronteiras ontológicas ou demonstrar de forma crítica que entes que entendemos como presentesa-si (Deus, Natureza, intelecto, percepções etc.) são de fato "mediados". 
Mas, ao fazer isso, a noção de mediação tende a tornar-se inerentemente polissêmica, avançando pouco conhecimento sobre o seu modus operandi. De fato, o conceito de medium em voga no campo dos estudos das mídias é extremamente extenso:

ele vai de registros pré-históricos das marés e das estrelas às mídias de massa contemporânea, incluindo transmissores físicos (como o ar e a luz), assim como esquemas de notação, sejam hieroglíficos, fonéticos ou alfanuméricos. Ele inclui tecnologias e artefatos, como a eletrificação, o telescópio, ou o gramofone ao lado de formas simbólicas e representações espaciais, como a perspectiva, o teatro, e a literatura como um todo (Vogl 2007:15).

Um efeito direto de tal ubiquidade é a autorreferencialidade ou remediação, como destacou McLuhan (1967), já que o objeto de um meio é sempre outro meio. Esses traços têm levado um grande número de autores a questionar qualquer possiblidade de uma definição fixa de medium (Siegert 2003; Horn 2007) e defender uma atenção mais apurada às historicidades, materialidades e relações potencializadas pelo que o mesmo Vogl (2007) chama de processos de tornar-se-meio ou devir-medium.

Poderíamos facilmente afirmar que os diferentes entes orgânicos e tecnológicos que listei em minha vinheta introdutória "medeiam" a devoção pentecostal nos níveis do pensamento, da fala e da ação. Mas tal tradução generalista não ajuda muito a entender como eles o fazem. Caixas de som, aparelhos de luz, cabos de eletricidade, celulares, rádios, manuais e tapetes de oração ou massageadores de costas realizam papéis distintos na oração, eventualmente formando arranjos ou cadeias operatórias (Lemonnier 1992: 25-31) específicas. A oração pode ser considerada uma forma de mediar transcendência e imanência ou de se comunicar com Deus, mas ela também é uma técnica corporal (Mauss 2003) e uma prática com "bens internos" (MacIntyre 2001; Reinhardt 2017a). ${ }^{5}$ O Profeta Ato invoca este aspecto quando distingue a oração enquanto pílula ou músculo, ou seja, uma tentativa pontual, às vezes desesperada, de se relacionar com Deus, ou um meio habitual de subjetivação religiosa através do qual emerge o que ele chama de um sujeito "orante", ou seja, moldado eticamente por esta prática. ${ }^{6}$

Os bens internos à oração pentecostal podem ser listas de virtudes prescritivas (Mahmood 2005), como os "frutos do Espírito" (Gálatas 5:22), paixões morais (Hirschkind 2006) que caracterizam o corpo pentecostal devoto, como o "zelo", o "fogo do espírito", ou o "júbilo", além de relações de intimidade (Luhrmann 2012) com Deus através de vozes, sonhos e imagens. No meu entender, todas essas potencialidade são, em última instância, embutidas de forma generativa ou "autopoiética" (Faubion 2001) na prática da oração enquanto técnica corporal, mais do que "mediadas" por ela. ${ }^{7}$ 
A analogia fornecida por Máquina de Oração, em que Espírito Santo/ondas de rádio :: profetas/aparelho de rádio, é ilustrativa nesse sentido, já que ela define as revelações proféticas tanto como experiências carismáticas espontâneas e soberanas advindas de Deus quanto como fruto do investimento moral e físico normativo do profeta: o trabalho da santificação, dos jejuns e da oração. Assim como as ondas de rádio, o Espírito Santo é invisível, apesar de certamente real e tangível para os pentecostais, emitindo informações e exercendo força afetiva em seus corpos. A analogia, no entanto, predica essas experiências viscerais no afinamento sensorial do converso (suas antenas ou botões de rádio) de acordo com a frequência do Espírito, o que significa adotar um certo estilo de vida: o tornar-se medium do crente ou, como eles mesmo preferem, "um bom vaso para o Senhor". Esse trabalho é fruto da graça, mas também de competências ético-espirituais adquiridas. O profeta destacou finalmente as contingências que interferem nesse processo, destacando que ele se dá em meio a "ruídos" normativos, especialmente agudos em Gana, onde o pentecostalismo tornou-se um movimento de massa marcado por vários níveis de devoção, polêmicas e uma pletora de "falsos profetas", o que requer constante reflexividade e discernimento (Daswani 2016).

Como argumento com maiores detalhes em outra ocasião (Reinhardt 2015), a melhor forma de se traduzirem processos pentecostais de devir medium - sejam eles orgânicos ou tecnológicos - para um léxico secular não é fazer um salto radical da noção mentalista de "crença", amplamente criticada na antropologia da religião contemporânea (ver Lindquist \& Coleman 2008), para o universo das sensações somáticas viscerais, como defendem os estudiosos da "religião material" (Engelke 2011), mas substituir a própria díade entre inteligível e sensível pelo que Deleuze chama de virtual e atual. Diferente do possível, que se relaciona com o real enquanto uma forma inteligível à espera de realização, Deleuze define o virtual em oposição formativa com o atual.

O virtual é plenamente real na medida em que é virtual. Exatamente o que Proust disse dos estados de ressonância deve ser dito do virtual: "Real sem ser atual, ideal sem ser abstrato"; e simbólico sem ser ficcional. De fato, o virtual deve ser definido estritamente como uma parte do objeto real - como se esse objeto tivesse uma de suas partes no virtual, que mergulha na dimensão objetiva (2001:208-09). ${ }^{8}$

Vozes, sonhos, visões e dádivas espirituais (como a glossolalia, curas espirituais, profecias e libertação de espíritos demoníacos), gêneros performáticos (como evangelismo, testemunhos e pregações, músicas e 
danças espirituais), e a cultura material pentecostal de maneira geral são todos imbuídos pelo Espírito Santo. Em uma ótica conversa, nenhuma dessas práticas ou artefatos "produz" ou "medeia" a presença divina. Elas afinam os sentidos humanos para suas múltiplas atualizações: vozes internas durante meditações silenciosas (Luhmann 2015), glossolalia extática durante sessões de oração (Reinhardt 2017a), fluxos transpessoais de poder através de palavras imbuídas pelo Espírito ou pela imposição de mãos (Coleman 2006; Campos \& Maurício Júnior 2013; Reinhardt 2014). Pode-se dizer que, em todos esses casos, o Espírito Santo é atualizado de forma plena, mas modular, através de autodiferenciações reconhecidas pelos praticantes por seus afetos singulares.

A virtualidade do Espírito Santo garante a unidade e a soberania do Deus monoteísta apesar desta intensa multiplicação modal. Revisitando a analogia do profeta Ato, podemos dizer que a potência total das ondas de rádio sempre escapará em alguma medida do aparelho profético dos homens de Deus, independente de seu nível de submissão. Tal irredutibilidade da presença divina ao mundo da criação e dos sentidos é, de fato, tão vital para a ética pentecostal quanto a sua atualização visceral, já que ela permite o florescimento da crítica no interior desta espiritualidade (Reinhardt 2016b). Tornar-se "renascido em Cristo" e "cheio do Espírito" não é automaticamente começar a experimentar Deus na primeira pessoa, em todos os seus modos possíveis, a todo tempo. É começar a habitar essas virtualidades e a mover-se na sua direção, um processo de longo prazo chamado em Gana de "amadurecimento espiritual". A contingência é parte intrínseca desse processo de tornar-se medium, que se baseia em larga medida em métodos de tentativa e erro.

Acredito que a forma visceral - apesar de modular, polêmica e contingente - com que os pentecostais interconectam-se com os afetos do Espírito Santo tende a escapar à noção de mediação. Em um sentido semiótico ou jurídico, um mediador é um signo, coisa ou pessoa que se coloca no lugar de um Objeto em sua ausência, enquanto o carisma pentecostal é um desdobramento relacional da presença divina. Antes de um Objeto a ser mediado, ele é um princípio difuso de animação da matéria; pneuma, um sopro divino (De Abreu 2009). A partir dessa ótica, eu prefiro definir a cultura material pentecostal, assim como suas extensões tecnológicas, como possuidora da função primária de facilitar "afinamentos atmosféricos" (Stewart 2011) para algo que já a constitui, ou seja, sua finalidade última não seria mediar uma força ausente, mas orquestrar ambientes de fé propícios para a atualização intensiva do Espírito Santo. 
De acordo com Kathleen Stewart, afinamentos atmosféricos são "processos composicionais de habitação dos espaços, capazes de transportar, gesticular, gestar mundos" (2011: 445). Atmosferas têm uma qualidade táctil difusa (háptica), logo as coisas nelas importam "não porque são representadas, mas porque têm qualidades, ritmos, forças, relações e movimentos" (2011: 445). É dentro dessas bolhas de fé e presença que o Espírito Santo ganha tração e movimento (Kirsch 2013), isto é, torna-se discernível sensorialmente porque se modaliza. Assim, o Espírito pode aflorar de dentro de fiéis, cair sobre eles, fluir através deles, recarregar seus corpos, e ser condensado e canalizado momentaneamente por condutores materiais, como os chamados "pontos de contato", que podem ser orgânicos, como as mãos, o óleo e o mel, ou mecânicos, como rádios ou tapetes de oração (ver abaixo).

É interessante notar como o engajamento pentecostal com o espaço ressoa fortemente com o modelo secular ecológico de autores como James Gibson (1979), para quem o espaço não é nem uma categoria mental, nem uma forma material vazia, mas um ambiente onde estamos imersos. Ele é irredutível a pontos e linhas geométricas equivalentes e intercambiáveis. O espaço, para Gibson, é composto por "pontos de observação" singulares, cruzados por várias formas de energia, produzindo informações sensoriais através de contato mecânico, químico e óptico. O que Gibson chama de o meio ou medium não se situa na nossa frente, mas é aquilo em que habitamos, a atmosfera sendo a sua expressão mais básica (Gibson 1979:16-31). O foco ecológico de Gibson em propriedades e materiais, ao invés de uma noção homogênea de materialidade e imaterialidade, pode ajudar antropólogos da religião a evitar o erro comum evocado por Ingold: "transitar de forma açodada da separação física entre o medium gasoso e a substância sólida para uma separação metafisica entre mente e matéria" (2011:22).

De acordo com Gibson, nós nos relacionamos com o meio atmosférico, com o ambiente e com seus nichos não pela mediação, o que seria redundante, mas através de formas de capacitação. Desencadeamos desses espaços de habitação affordances, palavra de difícil tradução, mas que Gibson define como "possibilidades de ação" de natureza emergente, logo irredutíveis tanto a "interpretações", de natureza subjetiva, quanto a "funções" materiais estáveis. ${ }^{9}$ As affordances são acumulativas. O ar, esse componente básico do meio, contém possibilidades humanas de ação como a respiração, a percepção visual, aural e olfativa. Affordances são também relacionais (a água não permite a locomoção para os humanos, mas sim para alguns insetos) e situadas (uma superfície vertical pode nos permitir instalar uma rede, mas ela também é capaz de proibir a passagem, o que pode ser uma affordance positiva ou negativa). 
Para Gibson, as técnicas e as tecnologias não nos separam do meio ou do ambiente através do artifício. Elas expandem o aparato humano e o ambiente simultaneamente ao estenderem suas possiblidades de ação. A técnica corporal da natação, por exemplo, torna o ambiente aquático "nadável" para os humanos, ao menos por algum tempo. Da mesma forma, acredito que diferentes técnicas pentecostais desencadeiam de sua relação com o ambiente o que Ann Taves (2013) chama de affordances especiais ao intensificarem e modularem a presença divina. O mesmo se dá com a tecnologia. O sociólogo Ian Hutchby chama de affordances tecnológicas "aspectos funcionais relacionais que enquadram de maneira não determinista as possibilidades de agência em relação a um objeto" (2001:444). Isto o ajuda a entender como as "funções" de um objeto tecnológico propostas pelos seus criadores frequentemente são excedidas por seu uso, como no caso do telefone, da internet, e de tantos outros. Affordances tecnológicas são irredutíveis tanto ao construtivismo social quanto ao determinismo tecnológico, permitindo-nos lidar com apropriações criativas da tecnologia, como no caso religioso, sem a necessidade de romantizá-las enquanto expressão de uma liberdade ou autonomia cultural de cunho imaterial. Essas inovações são na verdade engajamentos, a partir de uma sensibilidade religiosa cultivada, com possibilidades de ação desde sempre latentes nas tecnologias.

Michael (2000) demonstra como a natureza indeterminada das affordances tecnológicas tendem a formar "cascatas" no tempo, uma tornando-se condição de possiblidade da outra. Ele fornece um exemplo simples, mas ilustrativo: "as meias permitem o uso mais fácil de botas, que por sua vez permitem a anexação de pitões, que, por sua vez, permitem-nos escalar montanhas cobertas por neve, que, em si, tornam-se affordable, ou seja, escaláveis" (:112). As técnicas e as tecnologias pentecostais podem ser vistas operando de maneira similar quando "cascateiam" entre corpo e ambiente. Para um sujeito pentecostal espiritualmente "maduro", o meio, no sentido de Gibson, é grávido de intencionalidades divinas, mas elas precisam ser propriamente encadeadas de modo a engendrar as atmosferas que os pentecostais chamam de "reavivamentos". A seguir exploro a relação entre dois tipos de reavivamento pentecostal com as técnicas e as tecnologias.

\section{Igrejas móveis: louvações e orações radiofônicas}

Edificações, esqueletos burocráticos, infraestruturas tecnológicas e artefatos litúrgicos não constituem uma igreja para os pentecostais maduros. Eles são apenas matéria morta esperando para ser espiritualmente animada. As músicas e as danças espirituais, assim como a parafernália tecnológica 
que geralmente as acompanha - microfones, instrumentos musicais elétricos e aparelhos de som - são facilitadores dessas atmosferas de fé. Entendo o reavivamento pentecostal como um momento de comunhão e transubstanciação sem o foco de investimento sensorial explícito provido pelas coisas, uma espécie de totem aéreo, para ficar com a clássica figura durkheimiana, sem artefato ou substância que o capture simbolicamente. Esse modelo associativo, que julgo ser o fulcro da eclesiologia carismática, agrega comunidades não através da comunicação, mas enquanto comunicação (De Abreu 2009:162), sendo intrinsecamente transponível e performático.

Atmosfera de reavivamento: louvação

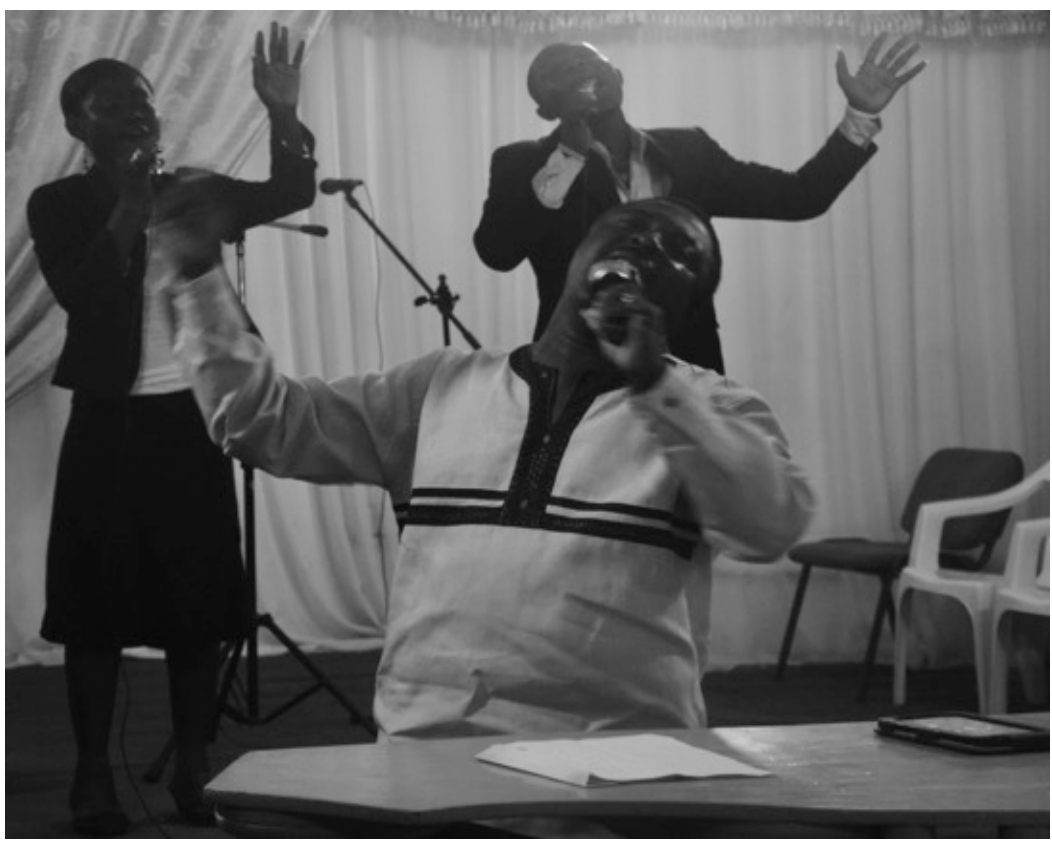

Assim como padrões de respiração ou coreografias, a performance musical pentecostal permite (no sentido de afford) a tessitura de "relações de afinação mútua" (Schutz 1951:79) entre fiéis, onde o Eu e o Você dão lugar a um Nós sincrônico. Enquanto parte de uma espiritualidade em que a música é uma prática carismática, o Nós produzido pela coperformance musical é habitado pelo peso de um Outro, como destacou o ministro de uma pequena igreja do bairro de Darkuman.

Quando o povo de Deus se une para adorá-lo, Deus se manifesta de uma forma nova. As vezes há manifestações físicas, como curas ou pessoas chorando, se ajoelhando, caindo ou rolando no chão. Às vezes, você está naquele ambiente e 
você sente que a coisa toda mudou. Você sente no ar. Deus pode se manifestar quando há pregação ou ensinamentos da Bíblia, mas a razão pela qual na maioria das vezes ele se manifesta durante as sessões de adoração e louvação é porque durante esses momentos os corações e as mentes das pessoas são "abertos" pelas músicas espirituais. Estamos todos movendo juntos, cantando em uma só voz, enquanto o pastor fica separado da congregação quando está pregando. Então, quando a gente canta e dança, o Espírito cai sobre nós ao mesmo tempo, e isso acontece de forma mais poderosa.

Gostaria de destacar que o modo espiritual a que se refere o ministro - que cai sobre os fiéis e estabelece entre eles uma simultaneidade - não ultrapassa uma fronteira ontológica, no sentido de vir "do além" ou estar no momento $\mathrm{x}$ ausente e no momento y presente. O Espírito estava desde sempre lá, em virtual omnipresença. Se a agência divina não opera em termos de fronteiras, pode-se dizer que a música promove um afinamento atmosférico propício para que o Espírito cruze um limiar afetivo (Sedgwick \& Frank 1995), assim como um objeto ganha em nitidez quando se move do fundo à frente de uma paisagem. De acordo com Gumbrecht, a palavra germânica Stimmung - que pode significar harmonia, humor ou atmosfera - deriva de Stimme, "voz" ou "afinar um instrumento": "Assim como o afinamento de um instrumento sugere, humores e atmosferas específicos são experimentado como um contínuo, como escalas musicais. Eles apresentam a si mesmos com nuances que desafiam nosso poder de discernimento e descrição, assim como a linguagem que potencialmente pode vir a capturá-los" (Gumbrecht 2012: 4, veja-se também Riedel 2015). Nesse sentido, a música pode ser considerada tanto um estágio bem delimitado nas séries litúrgicas pentecostais (louvação e adoração) como um substrato contínuo que sustenta todo o processo ritual, como exemplificado pela importância do ritmo para a oração coletiva ou o tom para a pregação.

Enquanto componentes desses arranjos inerentemente musicais, aparelhos de luz e som ajudam a gestar um ambiente de fé e presença, não como mediadores, mas como condutores atmosféricos que permitem o cruzamento de um limiar afetivo e o contato. Quando ele se encaixa de forma competente, "você sente no ar". Pude testemunhar o emergir de atmosferas reavivadas não somente no interior de igrejas propriamente ditas, mas também em casas, florestas, mercados populares e mesmo nos ônibus que cruzam as ruas barulhentas de Acra. Vejamos agora o caso de Seth, um amigo que recebeu a sua dádiva de línguas ao reproduzir essa eclésia móvel quando sintonizou seu rádio em um reavivamento radiofônico. 
Sessões de oração noturnas transmitidas pelo rádio ao vivo tornaram-se extremamente populares em Acra, sendo conhecidas como all-nights, uma versão resumida para "all-night prayer meetings". Audiências escutam allnights em suas casas, mas essas emissões também adentram os lugares mais profanos da paisagem urbana de Acra, como estações de transporte público e bares. Para esse público genérico, orações radiofônicas podem oferecer algum conforto e proteção espiritual. No entanto, seu engajamento com as possibilidades de ação embutidas nesses eventos midiáticos é no máximo difuso. Os ritmos intensos da oração pentecostal se diluem na paisagem sonora da cidade, o que não significa que as atmosferas que elas transportam não possam produzir efeitos surpreendentes.

Esse foi o caso de Seth, um pastor aprendiz de 25 anos, que se tornou renascido em Cristo quando ainda cursava a escola secundária. Não demorou muito para a conversão produzir visíveis efeitos em seu estilo de vida, mas por muitos anos Seth não conseguiu orar em línguas, até que um dia, durante seus estudos universitários, ele cruzou com um all-night na rádio.

Eu estava tendo sonhos e visões, mas eu não conseguia falar em línguas. Eu desejava ser cheio do Espírito. Um dia, eu estava na floresta de Achimota, onde outros estudantes costumavam ir para orar. Depois que oramos, pedi a um amigo mais velho que adorasse a Deus comigo. Então nós cantamos e adoramos Deus por algumas horas. Ele colocou suas mãos sobre mim e fez declarações [Ex. "Receba sua dádiva, em nome de Jesus"], mas nada aconteceu. Aquela noite, foi uma sexta à noite, eu voltei para o dormitório da universidade, em Legon, e sintonizei o rádio em um programa. Você sabe que aqui temos todos esses all-night ao vivo. Eu estava escutando um deles. Eu estava orando com eles e, de repente, eu me vi orando em línguas. Ninguém impôs suas mãos sobre mim, nada. Eu apenas me encontrei orando em línguas. Eu não sabia o que estava fazendo... Foi minha primeira vez. Esse era o meu primeiro ano na universidade. Depois disso, eu realmente senti um chamado, uma forte atração por Deus. Eu me tornei orante [prayerful]. As coisas de Deus começaram a crescer mais fortes em mim e mesmo a minha vida acadêmica foi deixada de lado.

Seth não falou muito sobre o programa de rádio em que sintonizou. Qual era o tema das orações? Quem era o ministro ou qual era a igreja que organizara o evento? Qual era a estação que o transmitia? Estes eram fatores inteiramente secundários se comparados ao que Seth escolheu sublinhar: a sua disposição. Seth desejava falar em línguas e estava à procura desta dádiva há algum tempo. Desejo adquire força moral ao direcionar a atenção, definida ela mesma por Gabriel Tarde como "desejo de especificar uma sensação nascente", logo, "desejo por aumentar uma crença presente" (1969:197). 
Para Tarde, tanto a atenção quanto a crença são forças libidinais, ou seja, físicas e morais, que se sedimentam no tempo em padrões repetitivos mais estáveis: o julgamento e a vontade.

Ao destacar a não separabilidade entre desejo, atenção e crença (geralmente compartimentalizados entre o corpóreo-volitivo e o mentalcognitivo), Tarde nos ajuda a entender o potencial eficaz da fé enquanto "certeza daquilo que esperamos e a prova das coisas que não vemos" (Hebreus 11:1). Pentecostais certamente "veem" aquilo pelo qual esperam - de milagres espetaculares a visões que antecipam a glória do Paraíso - mas isso acontece através de vislumbres heterogêneos e não por meio de uma conjugação absoluta de transcendência e imanência em uma fenomenologia religiosa. ${ }^{10}$ As atmosferas carismáticas materializam fé e presença e lentamente se esvaem, criando desejo por mais, ao invés de simplesmente estabilizarem a experiência. As orações radiofônicas deram a Seth uma oportunidade de submeter-se à força virtual do Espírito Santo através de uma disposição similar, de focar seus investimentos libidinais e afinar-se sensorialmente para uma atmosfera carregada de poder espiritual. Uma vez que seu desejo foi atendido e sua dádiva atualizada, os efeitos foram claramente autogenerativos (Faubion 2001). A dádiva de línguas não aplacou o desejo de Seth, mas o amplificou ainda mais, a ponto de começar a estabilizar-se em uma vontade singular, e assim minar seu comprometimento com um projeto de vida secular.

Sua fala destaca ainda que, diferente da lógica da mediação, as atmosferas pentecostais absorvem do medium ecológico uma direcionalidade difusa e contingente. De onde a impartição de Seth veio é difícil discernir, já que ninguém impôs suas mãos sobre ele. Trata-se de uma mão invisível mediada pelo rádio? Será que o Espírito simplesmente veio à superfície saindo de dentro dele, considerando que Seth já havia tido outras experiências carismáticas, como visões, anteriormente? A resposta foi deixada intencionalmente em aberto e pode não ser necessária. O que interessa é que as orações radiofônicas deram a Seth a possibilidade de plugar em um nicho reavivalista que ele buscava há anos. Ele foi para a floresta para receber sua dádiva, mas as orações radiofônicas a trouxeram para o seu quarto.

\section{Saturação: imposição de mãos e tapetes de oração}

O princípio teológico de que é possível absorver a unção, ou a graça ministerial, de pastores estabelecidos é extremamente difundida entre ministros pentecostais em Gana. Foi assim que Gideon, aluno da Central Bible School, articulou esse curioso fenômeno: 
Em Gana, nós temos o dique de Akosombo como uma fonte de eletricidade. Agora, se você precisa de eletricidade em sua casa, você não precisa viajar para Akosombo e canalizar essa energia direto da fonte. A eletricidade já foi trazida para a sua casa. Você tem tomadas e interruptores em volta de você. Se você precisa de eletricidade, conecte seu aparelho a uma dessas tomadas e ligue-o, você vai estar canalizando a energia de Akosombo. É o mesmo com a unção [...] Há pessoas que já foram ungidas pelo Senhor, então se você se conectar com elas, você receberá essa unção.

As expectativas em torno da unção devem ser entendidas em termos do que esse conceito sensível propicia. Primeiro, a unção permite a conversos reconhecer de maneira não contraditória a condensação vertical do carisma nos líderes de uma espiritualidade em que o poder carismático é, a priori, amplamente distribuído e horizontal. Ao mudar o jogo de linguagem do carisma das "dádivas espirituais" para a "unção", uma figura que captura do óleo, enquanto qualisigno, o atributo da gradação, pentecostais podem reconhecer e falar sobre intensidades de poder (mais ou menos ungido), enquanto as dádivas espirituais tendem a distribuir o carisma em termos dualísticos: ou você as recebeu ou não. Segundo, a unção permite aos conversos entender os homens de Deus como figuras porosas, que acumularam esse poder espiritual liquefeito até o limiar em que ele "vaza" por suas palavras e corpos. Campos e Murício Júnior (2013) destacam como o carisma pentecostal não apenas singulariza e diferencia líderes de seguidores, como no modelo weberiano, mas conecta ambos de maneia hierárquica através da circulação, "expandindo-se a partir e para além do líder carismático" (:255). O poder que emana dos homens de Deus é imbuído por potencialidades intercessórias (Coleman 2009), como a cura, mas também miméticas e pedagógicas, a impartição referindo-se exatamente a essa mistura: o milagre de um empoderamento carismático interpessoal (Reinhardt 2014, 2016a, 2017b).

A expectativa de "canalizar" a unção de ministros inclui suas extensões midiáticas, e essa sensibilidade já informara os comentários de Gideon acima. ${ }^{11}$ Como reflexo, em Gana, pastores tendem a listar entre seus "pais espirituais" tanto mentores com os quais eles se engajaram pessoalmente durante seu amadurecimento espiritual quanto figuras midiáticas com as quais se relacionam através do consumo de livros, CDs e DVDs. Assim, a unção anima esses mediadores técnicos com possibilidades de ação similares à imposição de mãos, a técnica de impartição mais convencional. Esta não é uma particularidade ganense ou africana. De acordo com a Charisma Magazine, uma revista pentecostal popular baseada na Flórida: 
"As relações ungidas [anointed fellowships], seja através do encontro com uma pessoa ungida, ou através de ensinamentos ungidos ouvidos em CDs e vídeos, são cruciais para o cultivo da unção em sua vida. Associe-se com o poder de Deus habitando onde Ele está".12

Assim como os espíritas franceses examinados por Stolow (2008), que comparavam o trabalho do médium a "uma máquina elétrica, que transmite mensagens telegráficas de um ponto da Terra a um outro muito distante" (:678), a analogia de Gideon entre Deus e a usina de Akosombo explora zonas de isomorfismo entre a agência espiritual e a infraestrutura da modernidade. Isto lhe permite abordar de forma intercambiável o carisma enquanto óleo e eletricidade de modo a sublinhar a fluidez e a transmissibilidade da unção. Deus, a fonte ativa, a barragem produtiva, escolheu humanos para operar como plugues disseminando o seu poder originário de maneira transversal. Em ambos os casos, o isomorfismo também permite "a contaminação mútua entre religião e tecnologia" (Stolow 2008: 669), através de inovações como o telégrafo espiritual ou a impartição midiática.

Plugues elétricos de fato oferecem aos pentecostais qualidades sensíveis "boas para se pensar" as influências dos homens de Deus. Assim como plugues, pregadores midiáticos estão simultaneamente próximos e distantes. Eles são "transformadores de escala" (Connor 2010: 6) e, ao conectar-se a eles, se está produzindo uma relação em um dado contexto e integrando-o em redes maiores, muitas vezes transnacionais (Robbins 2009). Muito do fascínio por essas celebridades em Gana tem a ver com a sua capacidade de amplificar influência e verticalizar o movimento ao permanecerem enraizadas em uma irmandade generalizada em Cristo e no Espírito Santo. Isto confere a seguidores/consumidores, como Gideon, um sentimento de proximidade e identificação com essas figuras icônicas apartadas pela distância social e geográfica. Deus pode usá-lo como usou a eles, e Deus pode usá-lo através deles, operando uma refração do carisma (Reinhardt 2015, 2016a).

O sucesso da impartição midiática naturalmente tem condicionantes: olhos e ouvidos atentos e desejosos e exercícios espirituais inovadores. O tapete de oração elétrico do profeta Ato adiciona a esse arranjo tecnoespiritual um elemento vital: saturação sônica. Ele se ajoelha no tapete e toca sermões de seus "pais espirituais" midiáticos através das caixas de som que o cercam enquanto ora em línguas. O profeta ora por sobre o fluxo sonoro da pregação, logo, o resultado é cacofônico. A prática que ele chama de "saturar-se em sermões" gera uma bolha sonora confusa, em que o aprendizado e a impartição, a absorção cognitiva dos sermões e a saturação no fluxo da unção que atravessa a voz desses homens de Deus justapõem-se de modo pouco intuitivo para os não iniciados. A prática tem uma dimensão 
explicitamente atlética, e pode durar horas. Extensão temporal, intensidade física e emocional visivelmente importam. Apesar de solitária neste caso, a impartição midiática pode se tornar altamente racionalizada enquanto uma técnica de discipulado e governo. Ela é um exercício espiritual obrigatório na escola bíblica da Lighthouse Chapel International, onde centenas de estudantes "saturam-se" na unção do fundador da igreja durante os sábados (Reinhardt 2014, 2016a). A atmosfera saturante é garantida, neste caso, por fones de ouvido e tocadores de MP3 contendo sermões digitalizados do fundador e líder da denominação.

Atmosfera saturante: impartição

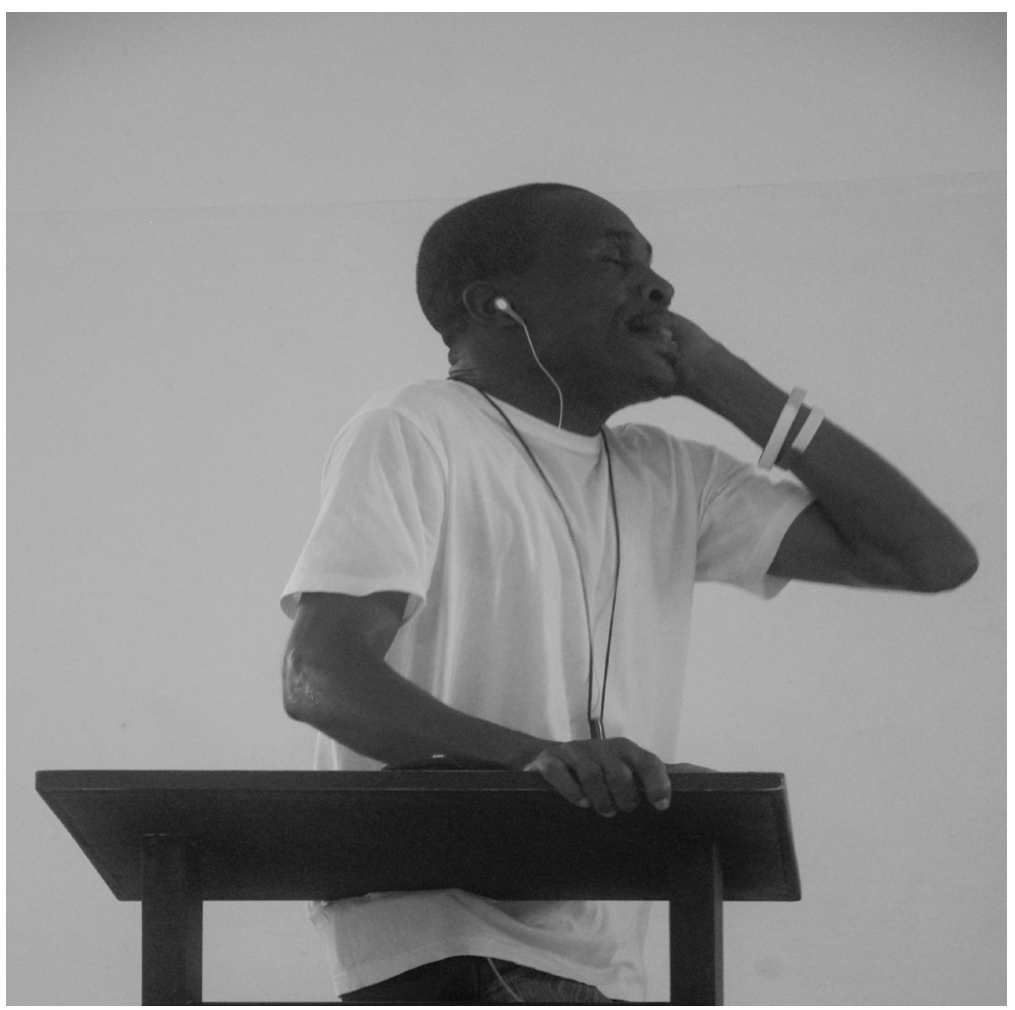

O Profeta Ato fez questão de esclarecer que a "saturação em sermões" excede o automatismo técnico ou tecnológico. De acordo com ele, a impartição elétrica "não é mágica", logo, se alguém como eu (para quem a oração não é nem mesmo uma pílula, quiçá um músculo) tentasse, nada aconteceria. Lealdade a Deus e aos pais espirituais foi outra condição evocada para a sua eficácia, sendo articulada através de comentários sobre a necessidade de "amar os homens de Deus que você está escutando", "segui-los" 
consistentemente, e "desejar o que eles têm". Desejo de mimetizar é a qualidade atentiva que acompanha a impartição como uma possibilidade de ação que cascateia entre o orgânico, o espiritual e o tecnológico. De modo a legitimar essa prática inovadora, ministros a enquadram como uma iteração do discipulado cristão face a face, assim como registrado na Bíblia (Reinhardt 2016a). Trata-se do mesmo processo que, por exemplo, transmitiu a unção do profeta Elias para seu aprendiz Elizeu, de Moisés a Josué, de Paulo a Timóteo. Como reflexo dessas teias tipológicas que se enraízam na temporalidade bíblica, fenômenos aparentemente incomensuráveis - como a imposição de mãos, a unção com óleo, o discipulado e o consumo de mídia eletrônica - tornam-se intercambiáveis porque são todos eles iterações de "relações ungidas". Nesse sentido, podemos dizer que, assim como na impartição radiofônica de Seth, a agência espiritual é atualizada neste caso não através do tapete elétrico, como um mediador inorgânico, mas através da atmosfera que esse aparelho ajuda a gestar, destacando-se um de seus componentes: a teia de relações replicáveis de filiação espiritual que todos os métodos de impartição contêm, sejam eles midiatizados ou não. Isto significa que, mais do que um encantamento da tecnologia, essa prática é primariamente um encantamento das relações enquanto plugues.

\section{Atmosferas e imaterialidade (transcendência)}

Ao invés de estabilizar a relação entre religião e tecnologia a priori em termos de identificação (religião-enquanto-mídia), optei neste artigo por uma abordagem mais exploratória, baseada em instrumentos conceituais situados e relacionais, como a díade virtual/atual, afinamentos atmosféricos e possibilidades de ação [affordances]. Ela me permitiu desagregar os vários sentidos e usos absorvidos e obscurecidos pelo conceito de mediação. Ainda mais importante, eu acredito que esta perspectiva ressoe de maneira mais produtiva com a própria sensibilidade de meus interlocutores sobre este tema, especialmente por reconhecer os papéis concomitantes da contingência e da visceralidade em seu engajamento com as tecnologias.

Primeiro, enquanto praticantes de uma espiritualidade que se emaranhou ecologicamente à tecnologia (Hansen 2006), os pentecostais não podem abordar esta relação de maneira generalista. Eles incorporam tecnologias particulares em função daquilo que elas permitem e impedem ao serem acopladas a práticas específicas. Em geral, pentecostais em Gana celebram os "ministérios de mídia" por seus efeitos evangelísticos, e frequentemente os legitimam enquanto "bíblicos", por exemplo, ao 
argumentarem que o próprio apóstolo Paulo também usou a mídia mais avançada de sua época - as cartas - para divulgar o evangelho. Mas os mesmos indivíduos que projetavam Paulo como o primeiro tele-evangelista, eventualmente lamentavam que os ministérios de mídia teriam acelerado a reprodução de cristãos "preguiçosos" e "imaturos" em Gana, reconhecendo que a midiatização amplifica o alcance quantitativo das mensagens religiosas a custo de perder o controle qualitativo sobre a sua recepção (Agha 2011). Em um tom mais espiritual, o profeta Ato celebrava que a internet havia "agilizado" a sua relação com o Espírito, já que agora ele podia ir a um internet café e usar concordâncias bíblicas on-line para interpretar sonhos e visões. Mas ele também me alertou sobre "demônios da internet" que têm se proliferado no meio digital e usado de vários subterfúgios para atacar, do "espírito da masturbação" aos ciber-crimes ocultos conhecidos em Gana como sakawa (Oduro-Frimpong 2014).

Identificar religião e tecnologias de mídia ontologicamente arrisca ignorar a reflexividade crítica dos consumidores religiosos. Isto é especialmente problemático em um contexto de normatividade disputada, como a África pós-colonial, em que a eficácia de qualquer medium religioso do corpo às palavras, da TV à internet - tende a ser explicitamente predicada em questões relativas à confiança (DeWitte 2012). Essa dimensão reflexiva do consumo midiático só pode ser entendida através de uma abordagem mais situada, que mantém algum grau de distância crítica sobre como esses domínios intersectam. Este aspecto tende a ser ofuscado por acadêmicos que selecionam a circulação na esfera pública, e não o consumo, como a sua escala privilegiada de representação. Isto os tem levado a assumir como axiomático que a cultura material pentecostal é "extremamente 'viva', já que é percebida como animada por forças numinosas" (Pype 2015: 361), ao invés de traçar como tal vivacidade se atualiza de maneira situada e relacional. De forma contrária, a noção de affordances requer não apenas uma mudança analítica de questões que buscam definições substanciais (o que é?) para questões que buscam procedimentos e qualificações da ação (como é?), algo válido para a própria categoria de religião (Asad 2001), mas também postula o inevitável entrelaçamento destes dois tipos de questões no cotidiano dos praticantes.

Segundo, destaquei que a contingência não é simplesmente alheia à normatividade religiosa. Argumentei que certa consciência da contingência é tão central para a devoção pentecostal quanto a atualização visceral das forças espirituais. É a própria justaposição entre visceralidade e contingência que torna a experiência carismática (Reinhardt 2016b), ou seja, fruto de uma intervenção transcendente, e não fruto da autoindução humana ou 
de artifícios tecnicamente construídos. Meus interlocutores reconhecem essa tensão quando enquadram o trabalho das técnicas de oração, artefatos, aparelhos, gêneros de performance e lugares em termos de "dar passagem" [yielding] ao Espírito, implicando que elas nunca garantem a sua atualização soberana. Diferente do conceito de mediação, que requer meios bem delimitados - o corpo, textos, imagens, artefatos orgânicos ou mecânicos - o conceito de afinamento atmosférico é capaz de reconhecer esse sentimento êmico de contingência porque trata primariamente de arranjos e orquestrações de materiais. Emergindo entre sujeito e ambiente enquanto expõe a sua participação, as atmosferas indexam "a realidade compartilhada do sujeito e do objeto da percepção" (Böhme 2017:20), logo a sua qualidade inerentemente musical, humoral ou meteorológica. Atmosferas são extremamente tácteis, mesmo que difusas em termos de origens. Elas apontam para um outro modo de conceber a imediação religiosa.

No paradigma da religião-enquanto-mídia, o problema da imediação tem sido tratado em termos da "propensão das medias de apagarem a si mesmas no ato de mediação" (Eisenlohr 2009:9). Isto é tido como fruto do trabalho de "ideologias semióticas" que hierarquizam suportes materiais e ênfases sensoriais em termos de graus de transparência, produzindo caixas pretas de imaterialidade. Assim, a articulação da sinceridade com uma "linguagem do coração", no caso protestante analisado por Keane (2007), postula uma conexão transparente entre voz e sentido que ofusca a óbvia materialidade da linguagem ela mesma. Meyer explora o paradoxo da mediação tecnológica/imediação religiosa como uma continuação desses processos ideológicos de apagamento semiótico, que selecionam e consagraram certas mídias como imateriais: "Desta forma, as mídias são autenticadas como parte inextricável do próprio transcendental que é alvo de - e, a partir de uma perspectiva de fora: invocado pela - mediação" (2015a:154).

Um modo alternativo de abordar a questão da imediação tem sido através da capacidade do hábito de incorporar de maneira simbiótica a externalidade dos artefatos através da encorporação [embodiment] (Ihde 1990). Esta perspectiva está na base da crítica de Hirschkind (2011) supracitada ao modelo da religião-enquanto-mídia e é explorada ricamente em sua etnografia sobre a circulação de fitas-cassete islâmicas no Cairo, cuja força afetiva é "predicada na plasticidade pedagógica [developability] do corpo enquanto um instrumento auditório" (2006:79). A imediação, sob este ângulo, não requer caixas pretas semióticas, já que se fundamenta no poder generativo da performatividade de sedimentar segundas naturezas. 
Como a bola para um jogador de futebol, a bengala para um cego ou a sonda para um dentista, os agregados tecnológicos tornam-se parte do medium corpóreo e campo perceptivo dos sujeitos religiosos através da habilitação ética.

Formas semióticas e pedagógicas de absorver mediadores são certamente parte importante do modo com que pentecostais ativam as possibilidades de ação embutidas em seu repertório material, incluindo a tecnologia. No entanto, ao focar nas atmosferas, minha intenção foi destacar uma forma alternativa de conceber a imediação, ou como prefiro chamar, transcendência. Ao invés de invisibilizar as tecnologias semioticamente ou contar com elas enquanto segundas naturezas, os afinamentos atmosféricos absorvem as tecnologias como parte do medium ecológico, respirando vida, movimento, Espírito, de maneira contingente através de arranjos que não precisam ser encantados em suas unidades objetais para se tornarem propícios para uma comunhão direta com Deus. Isto significa que a agência divina não se manifesta de maneira imanente nesta espiritualidade ao ultrapassar uma fronteira ontológica bem delimitada, vindo "do além", de acordo com a lógica dualista da presença/ausência, imaterial/material. O Espírito é uma virtualidade ubíqua que cruza um limiar afetivo (Sedgwick \& Frank 1995) ao atualizar-se de modos variados. É quando as atmosferas emergem, adquirem densidade visceral e ele é sentido "no ar". Isto se dá através da justaposição de modos específicos de presença e climas e humores também específicos. Destaquei aqui apenas dois: a atmosfera de simultaneidade extática gestada por uma versão transponível de igreja e as atmosferas saturantes que facilitam a impartição eletrônica.

Orar como uma máquina pode apenas ser uma qualidade desejada em uma espiritualidade que despreza o "ritualismo sem vida" de católicos e muçulmanos quando o automatismo se torna um meio para a conversão de propriedades digitais do tipo ligado/desligado, em propriedades analógicas associadas ao reavivamento, como "fogo" ou "estamina", qualidades que projetam a repetição não como reiteração, mas como aceleração. Essa constante conversão de propriedades extensivas em propriedades intensivas (DeLanda 2005), de fronteirais em limiares, está no cerne das atmosferas reavivalistas pentecostais, incluindo seu uso criativo da tecnologia e sua retórica ciborgue, que evoca qualisignos orgânicos e mecânicos de maneira intercambiável.

A dissolução atmosférica de artefatos delimitados em fluxos de materiais pertencentes ao medium ecológico obviamente não significa que os primeiros não ofereçam resistência normativa para essa espiritualidade, muito pelo contrário. Mas essas tensões não são organizadas em termos 
de imaterialidade ou materialidade, imediação ou mediação, mas entre o poder espiritual difuso das atmosferas reavivalistas e o poder de seus componentes materiais singulares de atraírem a atenção, o desejo e a crença dos participantes de maneira enganosa. Ministros divinizados, artefatos fetichistas ou tecnologias encantadas são todos exemplos de "heresias" evocadas pelos meus interlocutores. Eles são heresias ou "má objetificação" (Mitchell 2005) não porque são materiais, mas porque seduziram os praticantes a confundir uma versão ecológica da presença divina com um ou outro componente material das atmosferas que ajudaram a gestar, logo distraindo-os da contingência (e da transcendência) daquilo que julgam ser o autêntico Espírito de Deus.

Recebido em: 10 de novembro de 2019

Aprovado em: 19 de maio de 2020.

Bruno Reinhardt é doutor em antropologia sociocultural pela Universidade da Califórnia, em Berkeley, e professor adjunto do Departamento de Antropologia e do Programa de Pós-Graduação em Antropologia Social da Universidade Federal de Santa Catarina. Realiza pesquisas no campo da antropologia da religião e do secularismo no Brasil e em Gana.

https://orcid.org/0000-0003-3853-5927

E-mail: bmnreinhardt@gmail.com 


\section{Notas}

1 Impartição é a transferência de poder espiritual de um vaso humano para o outro, a imposição de mãos sendo seu meio privilegiado. A unção é uma graça especificamente ministerial, que é adicionada ao espectro mais democrático das dádivas espirituais. Veja-se Reinhardt (2016a, 2017b) e o que se segue por um debate mais detalhado sobre ambas as categorias.

2 De acordo com Peirce, um qualisigno é "uma qualidade que é um Signo", uma qualidade sensível que "não pode agir como um signo a não ser que seja encorporada [embodied]" (1955: 101). Para Peirce, as qualidades em si não passam de uma possibilidade lógica (ex., a "vermelhidão") e os entes são sempre agregados de fluxos de qualidades. Assim, qualidades só podem operar de maneira significativa através da similitude com um Objeto, ou seja, de maneira icônica. Munn (1992) explora, por exemplo, como o sistema de valores Massim é posto em circulação através da articulação opositiva de qualisignos relativos ao movimento (rapidez vs. lentidão), carga (leveza vs. peso) e iluminação (clareza vs. escuridão).

3 Variedade Ashanti do tronco linguístico Akan, majoritário em Gana.

4 Instrumento de sopro feito de chifre de cabra, de origem judaica antiga e presente na Bíblia.

5 De acordo com MacIntyre (2001), os bens internos às ações são as virtudes, que as movem a serem praticadas por si mesmas. Eles são opostos aos bens externos, que regem as ações instrumentais.

6 O profeta refere-se aqui à diferença entre o que Judith Butler (1993) chama de performance e perfomatividade. Performances são "atos delimitados", enquanto perfomatividade é fruto da "reiteração de normas que precedem, limitam, e excedem o sujeito da performance, e que, nesse sentido, não podem ser tomados como uma mera fabricação da 'vontade' ou 'escolha' desse sujeito" (:234).

7 Faubion (2001) apropria-se do termo autopoieses (autogeração) da cibernética e da teoria de sistemas para referir-se ao potencial criativo da pedagogia ética nos corpos e na subjetividade de seus praticantes. Esse modelo de ação enfatiza a ética enquanto habilitação, fundamentando-a de maneira dinâmica no próprio aparato pedagógico prescritivo das tradições, logo excedendo as duas opções dominantes no pensamento ocidental sobre a ética: o utilitarismo e a deontologia. Veja-se Mahmood (2005) e Hirschkind (2006) para dois usos influentes desta abordagem na antropologia da ética.

8 Veja-se Viveiros de Castro (2006) para uma definição do conceito ameríndio de "espírito" enquanto "multiplicidade virtual intensiva" (: 321) e Bialecki (2017) para a virtualidade do miraculoso entre pentecostais nos Estados Unidos. Ofereço um debate mais detalhado sobre a categoria em Reinhardt (2015). Este argumento ressoa com a abordagem de Corrêa (2016) para o "animismo crente". 
9 Velho (2001) propõe o termo "propiciação". Optei aqui, no entanto, por seguir a maioria dos autores brasileiros e manter o termo no original.

10 Sobre a dimensão antecipatória da ética e do somatismo religioso, veja-se Hirschkind (2006:173-204) sobre como "a escatologia é agora" para os mulçumanos egípcios; Bialecki (2017:22-47) sobre a temporalidade "já/não ainda" dos carismáticos americanos; e Reinhardt (2018) sobre a "força da espera" entre pentecostais em Gana.

11 O modus operandi da unção é de muitas maneiras análogo a outras categorias êmicas, como o aché na Santeria cubana (Beliso-de Jesús 2015) e a baraka no Sufismo (Schulz 2012), ambos também propiciando affordances tecnológicas inovadoras

12 http://www.charismamag.com/site-archives/639-charisma-channels/practicalchristianity/11816-get-plugged-in. Essa doutrina chegou em Gana com grande força principalmente através dos livros e das gravações do evangelista norte-americano Kenneth Hagin.

\section{Referências bibliográficas}

ASAD, Talal. 2001. "Reading a Modern Classic: W. C. Smith's 'The Meaning and End of Religion'". History of Religions, 40 (3):205-222.

BEHREND, Heike. 2003. "Photo Magic. Photographs in Practices of Healing and Harming in East Africa". Journal of Religion in Africa, 33 (2):129-145. BELISO-DE JESÚS, Aisha. 2015. Electric Santería: Racial and Sexual Assemblages of Transnational Religion. New York: Columbia University Press.

BENSAUDE-VINCENT, Bernadette \& BLONDEL, Christine (orgs.). 2008. Science and Spectacle in the European Enlightenment. Aldershot: Ashgate.

BIALECKI, Jon. 2017. A Diagram for Fire: Miracles and Variation in an American Charismatic Movement. Berkeley: University of California Press.
BLANTON Anderson. 2016. "The Prayer Machine: A Historical Sketch". Material Religion, 12 (1):99-101.

BÖHME, Gernot. 2017. The Aesthetics of Atmospheres. New York: Routledge.

BUTLER, Judith. 1993. Bodies that Matter. New York: Routledge.

CAMPOS, Roberta Bivar Carneiro \& MAURICIO J Ú N IOR, Cleonardo. 2013. "As formas elementares da liderança carismática: o verbo e a imagética na circulação do carisma pentecostal". Mana, 19 (2):249-276.

COLEMAN, Simon. 2006. "Materialising the Self: Words and Gifts in the Construction of Evangelical Identity". In: F. Cannell (org.), The Anthropology of Christianity. North Carolina: Duke University Press. pp.163-184.

. 2009. "Transgressing the self: making charismatic saints". Critical Inquiry, 35:417-39. 
CONNOR, Steven. 2010. "Plugs". Forum: University of Edinburgh Postgraduate Journal of Culture and the Arts, 10:1-9.

CORRÊA, Diogo. 2016. "O homem como pequeno deus": divindade e humanidade na cosmologia crente". In: Frédéric Vandenberghe \& Olivia von der Weid (orgs.), Novas Antropologias. Rio de Janeiro: Terceiro Nome. pp. 48-74.

CUNHA, Magali do Nascimento. 2007. A Explosão Gospel: um Olhar das Ciências Humanas sobre o Cenário Evangélico no Brasil. Rio de Janeiro: Mauad.

DASWANI, Girish. 2016. "'Prophet but not for Profit': Value and Virtue in Ghanaian Pentecostalism". Journal of the Royal Anthropological Institute, 20 (1):108-126.

DE ABREU, Maria Jose. 2009. "Breath, media and the making of Community Canção Nova, Brazil". In: Birgit Meyer (org.), Aesthetic Formations. Media, Religion and the Senses. Palgrave. New York: Macmillian. pp. 161-182.

DELANDA, Manuel. 2005. "Space: extensive and intensive, actual and virtual". In: Ian Buchanan \& Gregg Lambert (orgs.), Deleuze and Space. Edinburgh University Press. pp. 80-88.

DElbourgo, James. 2006. A Most Amazing Scene of Wonders: Electricity and Enlightenment in Early America. Harvard: Harvard University Press.

DELEUZE, Gilles. 2001. Difference and repetition. New York: Columbia University Press.

DERRIDA, Jacques. 2000. "Fé e Saber: as Duas Fontes da Religião nos Limites da Simples Razão". In: Jacques Derrida \& Gianni Vattimo (orgs.), A Religião. São Paulo: Estação Liberdade. pp. 11-89.
DEWITTE, Marleen. 2012. "The electric touch machine miracle scam: Body, technology, and the (dis) authentication of the Pentecostal supernatural". In: J. Stolow (ed.), Deus in Machina: Religion, Technology, and the Things in Between. New York: Fordham University Press. pp. 61-82. E ISENLOHR， Patrick. 2009 . "Technologies of the Spirit: Devotional Islam, Sound Reproduction and the Dialectics of Mediation and Immediacy in Mauritius". Anthropological Theory, 9 (3):273-96.

ENGELKE, Matthew. 2007. A Problem of Presence beyond Scripture in an African Church. Berkeley: University of California Press.

2010. "Religion and the Media Turn: A Review Essay". American Ethnologist, 37 (2):371-379.

2011. "Material Religion". In: $R$. A. Orsi (ed.), The Cambridge Companion to Religious Studies. Cambridge: Cambridge University Press. pp. 209-29.

FAUBION, James. 2001. "Toward an Anthropology of Ethics: Foucault and the Pedagogies of Autopoiesis". Representations ,74 (1):83-104.

GIBSON, James. 1979. The ecological approach to visual perception. Boston: Houghton Mifflin.

GIFFORD, Paul. 2004. Ghana's new Christianity: Pentecostalism in a globalizing African economy. Bloomington, Ind.: Indiana University Press.

GUMBRECHT, Hans. 2012. Atmosphere, Mood, Stimmung. On a Hidden Potential of Literature. Redwood City, California: Stanford University Press. HANSEN, Mark. 2006. "Media Theory". Theory, Culture and Society, 23 (2-3):297-306. 
HENARE, Amira; HOLBRAAD, Martin \& WASTELL, Sari (orgs.). 2007. Thinking Through Things: Theorising Artefacts Ethnographically. New York: Routledge.

HIRSCHKIND, Charles. 2006. The ethical soundscape cassette sermons and Islamic counterpublics. New York: Columbia University Press.

HORN, Eva. 2007. "There Are No Media". Grey Room 29:14-25, Winter 2008.

HORSFIELD, Peter. 2008. "Media". In: David Morgan (ed.), Key Words in Religion, Media, and Culture. New York: Routledge. pp. 111-22. 2011. "Media, Mediation, Religion". Social Anthropology, 19 (1):90-97.

HUTCHBY, Ian. 2001. "Technologies, Texts and Affordances". Sociology, 35 (2):441-456.

IHDE, Don. 1990. Technology and the Lifeworld: From Garden to Earth. Bloomington: Indiana University Press.

INGOLD, Tim. 2011. Being Alive: Essays on Movement, Knowledge and Description. New York: Routledge.

KEANE, Webb. 2007. Christian Moderns Freedom and Fetish in the Mission Encounter. Berkeley: University of California Press.

KIRSCH, Thomas. 2013. "Intangible Motion: Notes on the Morphology and Mobility of the Holy Spirit". In: Ruy Llera Blanes \& Diana Espírito Santo (eds.), The Social Life of Spirits. Chicago: University of Chicago Press. pp. 33-51.

KLASSEN, Pamela. 2011. Spirits of Protestantism medicine, healing, and liberal Christianity. Berkeley: University of California Press.

LEMONNIER， Pierre. 1992. Elements for an Anthropology of Technology. Michigan: Museum of Anthropological Research.
LINDQUIST, Galina \& COLEMAN, Simon. 2008. "Introduction: Against Belief?". Social Analysis, 52 (1) 1:118.

LUHRMANN, Tanya. 2012. When God talks back: understanding the American evangelical relationship with God. New York: Alfred A. Knopf.

MACHADO, Carly. 2014. "Introdução ao Dossiê Religião e Mídia". Religião \& Sociedade, 34 (2):139-145.

MACINTYRE, Alasdair. 2001. Depois da Virtude. Bauru: EDUSC.

MAHMOOD, Saba. 2005. Politics of Piety: The Islamic Revival and the Feminist Subject. Princeton: Princeton University Press.

MAUSS, Marcel. [1935] 2003. "As Técnicas do Corpo". In:__, Sociologia e antropologia. São Paulo: CosacNaify. pp. 399-422.

MCLUHAN, Marshall. 1967. Understanding media: the extensions of man. London: Routledge \& Kegan Paul.

MEYER, Birgit. 2011. "Medium". Material Religion, 7(1): 58-67. . 2015a. "Mediação e Imediatismo: formas sensoriais, ideologias semióticas e a questão do meio". Campos: Revista de Antropologia, 16 (2):145-64. . 2015b. Sensational Movies: Video, Vision, and Christianity in Ghana. Berkeley: University of California Press.

MEYER, Birgit \& MOORS, Annelise (orgs). 2006. Religion, Media and the Public Sphere. Bloomington: Indiana University Press.

MEYER, Birgit \& PELS, Peter (orgs.), 2003. Magic and Modernity: Interfaces of Revelation and Concealment. Stanford: Stanford University Press.

MICHAEL, Mike. 2000. "These Boots are made for Walking...' Mundane Technology, the Body and HumanEnvironment Relations". Body and Society, 6:107-26. 
MUNN, Nancy. 1992. The Fame of Gawa: a Symbolic Study of Value Transformation in a Massim (Papua New Guinea) society. Durham: Duke University Press.

ODURO-FRIMPONG, Joseph. 2014. "Sakawa Rituals and Cyberfraud in Ghanaian Popular Video Movies". African Studies Review, 57 (2):131147.

PEIRCE, Charles. S. 1955. "Logic as Semiotic: the Theory of Signs". In: Philosophical Writings of Peirce. New York: Dover.

PYPE, Katrien. 2015. "The Liveliness of Pentecostal-Charismatic Popular Culture in Africa". In: Pentecostalism in Africa. Presence and Impact of Pneumatic Christianity in Postcolonial Societies. Amsterdam: Brill. pp. 345378.

REINHARDT, Bruno. 2014. "Soaking in Tapes: The Haptic Voice of Global Pentecostal Pedagogy in Ghana". Journal of the Royal Anthropological Institute, 20 (2):315-36.

. 2015. "A Christian plane of

immanence?: Contrapuntal reflections on Deleuze and Pentecostal spirituality". HAU: Journal of Ethnographic Theory, 5 (1):405.

2016a. "De epifania a método: a teopolítica do testemunho em um seminário pentecostal em Gana". Religião \& Sociedade, 36 (2):44-70.

. 2016b. "'Don't Make It a Doctrine'. Material Religion, Transcendence, Critique". Anthropological Theory, 16 (1):75-97.

. 2017a. "Praying until Jesus returns: commitment and prayerfulness among charismatic Christians in Ghana". Religion, 47 (1): 51-72.
. 2017b. "The Pedagogies of Preaching: Skill, Performance, and Charisma in a Pentecostal Bible School from Ghana". Journal of Religion in Africa, 47:72-107.

. 2018. "Temporalidade, Ética e Contingência na Pós-colônia Africana: Esperando por Deus em Gana". Ilha: Revista de Antropologia, 19 (2):175-212.

RIEDEL, Friedlind. 2015. "Music as Atmosphere: Lines of Becoming in Congregational Worship". Lebenswelt, 6:80-111.

SCHMIDT, Leigh Eric. 2000. Hearing things: religion, illusion, and the American enlightenment. Cambridge: Harvard University Press.

SCHULZ, Dorothea. 2012. Muslims and New Media in West Africa: Pathways to God. Bloomington: Indiana University Press.

SEDGWICK, Eve \& FRANK, Adam. 1995. "Shame in the Cybernetic Fold: Reading Silvan Tomkins". Critical Inquiry, 21 (2):496-522.

SIEGERT, Bernhard. 2003. "There Are No Mass Media". In: Hans Ulrich Gumbrecht \& Michael Marrinan (eds.), Mapping Benjamin: The work of art in the digital age. Stanford: Stanford University Press. pp. 30-38. STEWART, Kathleen. 2011. "Atmospheric Attunements". Environment and Planning D: Society and Space, 29:445- 453

STOLOW, Jeremy. 2005. "Religion and/as Media. Theory, Culture and Society, 22 (4):119-146. 2008. "Salvation by Electricity". In: Hent de Vries (ed.), Religion: Beyond a Concept. New York: Fordham University Press. pp. 668-86.

. 2013. Deus in machina religion, technology, and the things in between. New York: Fordham University Press. 
TARDE, Gabriel. 1969. "Belief and desire". In: Gabriel Tarde on communication and social influence; selected papers. Chicago: University of Chicago Press. pp. 195-208.

TAVES, Ann. 2013. "Non-Ordinary Powers: Charisma, Special Affordances and the Study of Religion". In: Dimitris Xygalatas \& Lee McCorkle (eds.), Mental Culture: Towards a Cognitive Science of Religion. Durham: Acumen. pp. 80-97.

VELHO, Otávio. 2001. "De Bateson a Ingold: passos na constituição de um paradigma ecológico". Mana, 7 (2):133-140.

VIVEIROS DE CASTRO, Eduardo. 2006. "A Floresta de Cristal: Notas sobre a Ontologia dos Espíritos Amazônicos". Cadernos de Campo, 14-15:319-338.

VOGL, Joseph. 2007. "Becoming-media: Galileo's Telescope". Grey Room, 29:14-25.

VRIES, Hent de. 2001. "Of Miracles and Special Effects". International Journal for Philosophy of Religion, $50(1 / 3): 41-56$. 
DESAGREGANDO A MEDIAÇÃO: TECNOLOGIAS E ATMOSFERAS RELIGIOSAS

\section{Resumo}

Neste artigo aponto para certos limites intrínsecos ao conceito de mediação, que tem dominado debates recentes sobre a relação entre religião e tecnologia na antropologia e além. Inspirado etnograficamente pelas técnicas e tecnologias de oração utilizadas por um profeta pentecostal baseado em Acra, Gana, meu argumento destaca a qualidade atmosférica da fé pentecostal, fruto de uma concepção de agência divina a um só tempo difusa e intensiva, contingente e visceral. Destaco como essa relação ecológica com a presença condiciona o engajamento pentecostal com a tecnologia, que tende a operar menos como uma forma de mediação de algo que os excede e mais como uma forma de afinamento sensorial para algo que os constitui. Proponho um conjunto alternativo de conceitos capazes de desagregar as diversas operações homogeneizadas pela noção de mediação, como virtualidade, possibilidades de ação (affordances) e afinamento atmosférico.

Palavras-chave: Religião e Tecnologia, Atmosferas, Possibilidades de ação (affordances), Pentecostalismo, Gana.
UNPACKING MEDIATION: TECHNOLOGIES AND RELIGIOUS ATMOSPHERES

\section{Abstract}

In this article I propose a critique of the concept of mediation, which has dominated recent debates on religion and technology in anthropology and beyond. Inspired by the prayer techniques and technologies mobilized by a Pentecostal prophet based in Accra, Ghana, I highlight the atmospheric quality of pentecostal faith, fruit of a conception of divine agency simultaneously diffuse and intensive, contingent and visceral. I argue that Pentecostals' ecological relation with divine presence conditions their engagement with technology, which operates less as a form of mediation between "here" and "beyond", and more as a form of attunement to something that already constitutes them. I propose an alternative set of concepts able to unpack the various operations often homogenized by the concept of mediation, such as virtuality, affordances, and atmospheric attunements.

Keywords: religion and technology; atmospheres; affordances; Pentecostalism; Ghana. 
DISGREGANDO LA MEDIACIÓN:

TECNOLOGÍAS Y ATM OSFERAS

\section{RELIGIOSAS}

\section{Resumen}

En este artículo señalo ciertos límites intrínsecos al concepto de mediación, el cual ha dominado debates recientes sobre la relación entre religión y tecnología en la antropología y más allá. Inspirado etnográficamente por las técnicas y tecnologías de la oración utilizadas por un profeta popular, residente en Accra, Ghana, mi argumento destaca la calidad atmosférica de la fe pentecostal como fruto de una manera de concebir la agencia divina al mismo tiempo difusa e intensiva, contingente y visceral. Pongo en destaque cómo esa relación ecológica con la presencia condiciona la interdependencia pentecostal a la tecnología, que tiende a funcionar menos como una forma de mediación de algo que los sobrepasa y más como una forma de afinamiento sensorial a algo que los constituye. Propongo un conjunto alternativo de conceptos capaces de disgregar las diversas operaciones homogeneizadas por el concepto de mediación, como virtualidad, posibilidades de acción (affordances) y afinamiento atmosférico.

Palabras clave: religión y tecnología, atmósferas, affordances, Pentecostalismo, Ghana. 